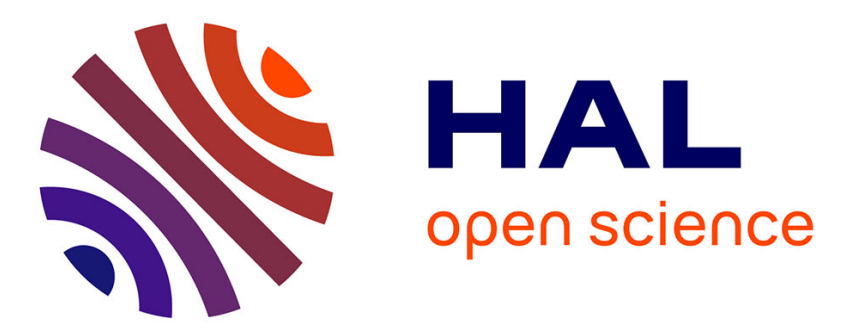

\title{
A comparative study of harmonic currents extraction by simulation and implementation
}

\author{
Llia Merabet, Salah Saad, Djaffar Ould Abdeslam, Amar Omeiri
}

\section{To cite this version:}

Llia Merabet, Salah Saad, Djaffar Ould Abdeslam, Amar Omeiri. A comparative study of harmonic currents extraction by simulation and implementation. International Journal of Electrical Power \& Energy Systems, 2013, 53 (-), pp.507-514. 10.1016/j.ijepes.2013.05.003 hal-00985541

\section{HAL Id: hal-00985541 \\ https://hal.science/hal-00985541}

Submitted on 30 Apr 2014

HAL is a multi-disciplinary open access archive for the deposit and dissemination of scientific research documents, whether they are published or not. The documents may come from teaching and research institutions in France or abroad, or from public or private research centers.
L'archive ouverte pluridisciplinaire HAL, est destinée au dépôt et à la diffusion de documents scientifiques de niveau recherche, publiés ou non, émanant des établissements d'enseignement et de recherche français ou étrangers, des laboratoires publics ou privés. 


\title{
A Comparative Study of Harmonic Currents Extraction by Simulation and Implementation
}

\author{
${ }^{(1)}$ L. Merabet, ${ }^{(2)}$ S. Saad, ${ }^{(3)}$ D. Ould Abdeslam, ${ }^{(4)}$ A. Omeiri \\ (1), (2), (4) Laboratoire Systemes Electromécaniques Badji-Mokhtar University, BP 12, Annaba 23000, Algeria \\ ${ }^{(3)}$ MIPS laboratory, Université de Haute Alsace, 4 rue des frères lumière, 68093 Mulhouse, France \\ ${ }^{(1)}$ Email: lei elt@yahoo.fr, ${ }^{(2)}$ Email: saadsalah2006@yahoo.fr, ${ }^{(3)}$ Email:djaffar.ould-abdeslam@uha.fr, \\ ${ }^{(4)}$ Email: Omeiri-amar@univ-annaba.org
}

\begin{abstract}
The aim of the present work is to obtain a perfect compensation by extracting accurate harmonic currents. The objective is to avoid the consequences due to the presence of disturbances in the power system. A comparative study of harmonic currents extraction by simulation and implementation is carried out for two different techniques. The first technique is based on the instantaneous powers, taking advantage of the relationship between current and the power transformed from the supply source to the loads. The second is based on ADALINE neural network. The neural method can estimate the harmonic terms individually and online, therefore, the APF can realise a selective compensation. The developed architectures are validated by computer simulation and experimental tests. The algorithms are implemented in the dSPACE Board in order to show the effectiveness and capability of each technique. The results have demonstrated that the speed and the accuracy of the ADALINE can improve greatly the performances of active power filters.
\end{abstract}

Keywords-- Active Power Filter, Harmonics Currents, ADALINE Neural Network, $p-q$ theory, Fourier Series.

\section{INTRODUCTION}

The intensive use of power converters as rectifiers produces non sinusoidal current in the a.c. supply. Therefore, the voltage in the point of common coupling will contain harmonic components. Furthermore, harmonic voltages and currents propagate into the supply system, increase losses, generate measurement errors, interfere with other consumers, and cause serious problems of electromagnetic compatibility [1].

Currently, active power filters have been widely used, studied and presented as a solution to cancel harmonics from power network. These filters are classified into shunt active power filter, series active power filter, hybrid filters (parallel passive filter and series active power filter) and finally, Unified Power Quality Conditioner UPQC (series active power filter and shunt active power filter) [1], [2].

Shunt active filter [3], injects compensating harmonic currents into the power system to mitigate harmonic contained in the loads.

Actually, several control methods such as sliding mode control [4], wavelet method [5], fuzzy control [6], [7], adaptive neural network control [8], neuro-fuzzy control [9], and fundamental magnetic flux compensation [10], have been proposed and used to control harmonic currents and dc voltage of power filters. These controllers are also employed to improve active power filter performances and replace the conventional PID controllers [11].

A perfect compensation is necessary to avoid the consequences due to harmonics. The estimation of current references constitutes an important part in the control of active power filters (APFs) used in power systems. Although many identification techniques and strategies have been developed such as methods based on FFT (Fast Fourier Transformation) in the frequency domain, and the methods based on instantaneous power calculation in the time -domain. Instantaneous active and reactive theory ( $p-q$ theory) introduced by Akagi [1], is a well-known compensating strategy. This method requires the transformation of both supply and load currents/voltages from the abc reference frame to the $\alpha-\beta$ reference frame. This method operates very well for harmonics cancellation and reactive power compensation, simultaneously, under balanced source voltages.

However, researchers from many scientific disciplines are developing and designing artificial neural networks (ANNs) to solve problems in pattern recognition, prediction, optimization, associative memory and control [12]-[15]. Artificial neural networks are successfully applied to power systems, especially for harmonic extraction [16]-[19].

The ADALINE, which is a type of ANNs, and its new application for analysis of power quality, has the advantages of being simply built and easily implemented through hardware. The results of frequency tracking, [20][22] and especially harmonics detection, [8], [16]-[18] demonstrate that the ADALINE and its algorithm can be applied to the precise analysis for power quality. The learning capacity of the ANNs enables online adaptation to any change in electrical network parameters.

Many applications, such as harmonic monitoring, may require the extraction of a limited number of individual harmonics as the $5^{\text {th }}$ and the $7^{\text {th }}$ harmonics which are the most harmful. The ADALINE proposed by Widrow and Hoff [23], can estimate the harmonic terms individually 
and online.

In this paper, two techniques for harmonic currents extraction are developed and compared. The first technique is based on the instantaneous powers theory ( $p$ $q$ theory) and the second technique is based on ADALINE neural method. Simulations and experimental tests are carried out in order to show the effectiveness and the capability of each technique. The results demonstrate that the ADALINE neural method is more efficient and easy to implement.

\section{PRINCIPLE OF SHUNT APF}

The APF is a voltage source inverter connected to the three-phase line through the inductor L (Fig.1). This inverter injects an appropriate current into the system to compensate harmonics currents that are responsible for power network pollution.

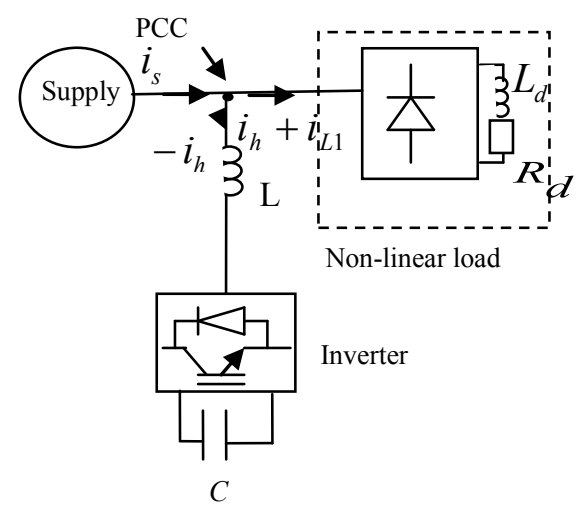

Fig.1. Principle of APF

\section{INSTANTANEOUS POWER THEORY ( $p-q$ theory)}

The instantaneous power method ( $p-q$ theory) [1], [2] is defined on the basis of the instantaneous values of voltage and current waveforms in a three phase power system (Fig. 2).

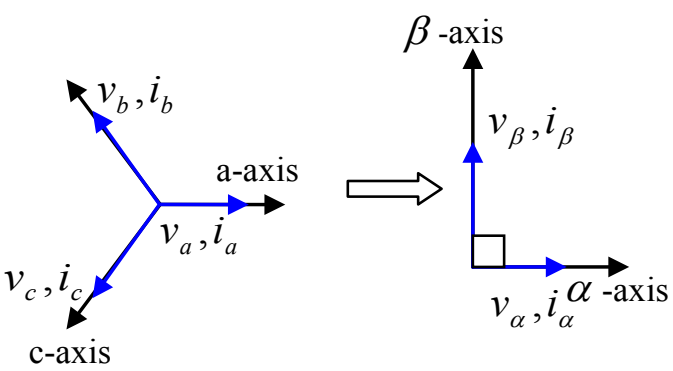

Fig.2. the instantaneous space vectors

Using the Clarke transformation, these three-phase vectors are transformed to the orthogonal $\alpha, \beta, o$ coordinate system.

$$
\begin{aligned}
& {\left[\begin{array}{l}
v_{0} \\
v_{\alpha} \\
v_{\beta}
\end{array}\right]=\sqrt{\frac{2}{3}}\left[\begin{array}{ccc}
\frac{1}{\sqrt{2}} & \frac{1}{\sqrt{2}} & \frac{1}{\sqrt{2}} \\
1 & -\frac{1}{2} & -\frac{1}{2} \\
0 & \frac{\sqrt{3}}{2} & -\frac{\sqrt{3}}{2}
\end{array}\right]\left[\begin{array}{l}
v_{s a} \\
v_{s b} \\
v_{s c}
\end{array}\right]} \\
& {\left[\begin{array}{c}
i_{0} \\
i_{\alpha} \\
i_{\beta}
\end{array}\right]=\sqrt{\frac{2}{3}}\left[\begin{array}{ccc}
\frac{1}{\sqrt{2}} & \frac{1}{\sqrt{2}} & \frac{1}{\sqrt{2}} \\
1 & -\frac{1}{2} & -\frac{1}{2} \\
0 & \frac{\sqrt{3}}{2} & -\frac{\sqrt{3}}{2}
\end{array}\right]\left[\begin{array}{l}
i_{s a} \\
i_{s b} \\
i_{s c}
\end{array}\right]}
\end{aligned}
$$

Since the load is balanced, and there is no neutral line, the system does not have a zero-sequence, $v_{0}$ and $i_{0}$ are equal to zero and the system equations are simplified as shown below:

$$
\begin{aligned}
& {\left[\begin{array}{l}
v_{\alpha} \\
v_{\beta}
\end{array}\right]=\sqrt{\frac{2}{3}}\left[\begin{array}{ccc}
1 & -\frac{1}{2} & -\frac{1}{2} \\
0 & \frac{\sqrt{3}}{2} & -\frac{\sqrt{3}}{2}
\end{array}\right]\left[\begin{array}{l}
v_{s a} \\
v_{s b} \\
v_{s c}
\end{array}\right]} \\
& {\left[\begin{array}{l}
i_{\alpha} \\
i_{\beta}
\end{array}\right]=\sqrt{\frac{2}{3}}\left[\begin{array}{ccc}
1 & -\frac{1}{2} & -\frac{1}{2} \\
0 & \frac{\sqrt{3}}{2} & -\frac{\sqrt{3}}{2}
\end{array}\right]\left[\begin{array}{l}
i_{s a} \\
i_{s b} \\
i_{s c}
\end{array}\right]}
\end{aligned}
$$

The conventional instantaneous power in a three-phase system $p$ and $q$ is based on the following equation:

$$
\begin{aligned}
& p=v_{\alpha} i_{\alpha}+v_{\beta} i_{\beta} \\
& q=v_{\alpha} i_{\beta}-v_{\beta} i_{\alpha}
\end{aligned}
$$

Equations (5) and (6) are written in matrix form as shown in equation (7).

$$
\left[\begin{array}{l}
p \\
q
\end{array}\right]=\left[\begin{array}{ll}
v_{\alpha} & v_{\beta} \\
-v_{\beta} & v_{\alpha}
\end{array}\right]\left[\begin{array}{l}
i_{\alpha} \\
i_{\beta}
\end{array}\right]
$$

The currents can be deduced by:

$$
\begin{aligned}
& {\left[\begin{array}{l}
i_{\alpha} \\
i_{\beta}
\end{array}\right]=\frac{1}{\Delta}\left[\begin{array}{cc}
v_{\alpha} & -v_{\beta} \\
v_{\beta} & v_{\alpha}
\end{array}\right]\left[\begin{array}{l}
p \\
q
\end{array}\right]} \\
& \Delta=v_{\alpha}^{2}+v_{\beta}^{2}
\end{aligned}
$$

The active and reactive powers as calculated from equation (7) can be split into DC and AC components as illustrated below:

$$
\left[\begin{array}{l}
p \\
q
\end{array}\right]=\left[\begin{array}{l}
\bar{p}+\tilde{p} \\
\bar{q}+\widetilde{q}
\end{array}\right]
$$

Where, $\bar{p}$ and $\bar{q}$ are the DC active and reactive powers and $\widetilde{p}$ and $\widetilde{q}$ are the AC active and reactive powers. Two low-pass filters are needed to extract $\widetilde{p}$ and $\tilde{q}$. If the system is designed to compensate 
harmonics and reactive power drawn by the load, it is necessary to eliminate the two components of instantaneous reactive power $(\bar{q}$ and $\widetilde{q})$ as well as the $\mathrm{AC}$ component of the instantaneous real power $(\tilde{p})$.

The $\alpha$ and $\beta$ reference currents that are needed to achieve the required compensation are calculated by the following equations:

$$
\left[\begin{array}{c}
i_{\text {oref }} \\
i_{\text {Bref }}
\end{array}\right]=\frac{1}{\Delta}\left[\begin{array}{cc}
v_{\alpha} & -v_{\beta} \\
v_{\beta} & v_{\alpha}
\end{array}\right]\left[\begin{array}{l}
\tilde{p} \\
\widetilde{q}+\bar{q}
\end{array}\right]
$$

The obtained three-phase harmonic currents that the inverter has to inject into the supply are given by:

$$
\left[\begin{array}{l}
i_{r e f a} \\
i_{r e f b} \\
i_{r e f c}
\end{array}\right]=\sqrt{\frac{2}{3}}\left[\begin{array}{rr}
1 & 0 \\
-\frac{1}{2} & \frac{\sqrt{3}}{2} \\
-\frac{1}{2} & -\frac{\sqrt{3}}{2}
\end{array}\right]\left[\begin{array}{l}
i_{\alpha r e f} \\
i_{\beta r e f}
\end{array}\right]
$$

If the system is unbalanced it is necessary to calculate the direct voltage components. This can be achieved by a conventional PLL, or a neural PLL [20]-[22], [24].

\section{DIPHASE CURRENTS NEURAL METHOD}

Diphase currents neural method introduced in [8] is simple with a linear approach based on the ADALINE Neural Network. This method works in the DQ-space and can be easily implemented.

\section{A. ADALINE neural network algorithm}

The ADALINE neural network [18], [19], is a linear combiner that uses the LMS algorithm for its operation. Figure 3 shows the structure of the ADALINE where $x$ is an input vector with $\mathrm{n}$ dimension and $w$ is the weight vector. The output of the ADALINE can be calculated for any input $x_{i}$ as presented below:

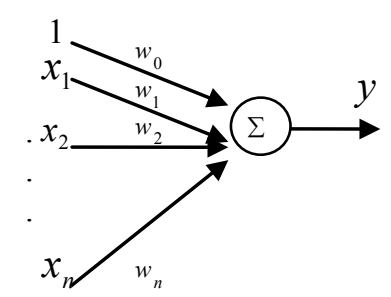

Fig.3. Basic architecture of ADALINE neural network

$y=\sum_{i=0}^{n} x(i) w(i)=x^{T} w$

\section{B. Learning rules}

Widrow proposed the LMS (least mean square) algorithm, which has been extensively applied in adaptive signal processing and adaptive control [23].
The $\mu$ LMS algorithm is structured as follows:

1: Initialise weights and learning rate $\mu$

2: Present new inputs and desired output $(d)$ of the neuron.

3: Calculate the output $(y)$ according to the equation (13)

4: Calculate the error: $\delta=d-y$

5: Update weights, at simple time $k$ according to the equation below:

$W(k+1)=W(k)+\mu\left(d_{k}-y_{k}\right) x(k)$,

Where $d$, the desired output, and $\mu(0 \prec \mu \prec 1)$ is the learning rate.

The weights of the Adaline $\left(w_{i}\right)$ are enforced to converge to the values representing real harmonics content in power distribution network.

\section{Diphase harmonics currents extraction}

The Diphase Current Method works in the DQ-space and provides an excellent dynamic response for the online identification of fluctuating harmonics. If the system is unbalanced, the direct angle $\theta_{d}$ must be calculated. This can be achieved by a conventional or a neural PLL method.

According to Fourier series, the three-phase load currents can be expressed as:

$\left[\begin{array}{l}i_{L a} \\ i_{L b} \\ i_{L c}\end{array}\right]=i_{1}\left[\begin{array}{l}\cos \left(\omega t-\alpha_{1}\right) \\ \cos \left(\omega t-\alpha_{1}-2 \pi / 3\right) \\ \cos \left(\omega t-\alpha_{1}+2 \pi / 3\right.\end{array}\right]+\sum_{n=2}^{N} i_{n}\left[\begin{array}{l}\cos \left(n \omega t-\alpha_{n}\right) \\ \cos \left(n \omega t-\alpha_{n}-2 \pi / 3\right) \\ \cos \left(n \omega t-\alpha_{n}+2 \pi / 3\right.\end{array}\right]$

This load current can be written in the DQ-space with $i_{D}$ and $i_{Q}$ by applying respectively the Clarke transformation $T_{32}^{T}$ and Park transformation with an angle of $(-\omega t)$ :

$\left[\begin{array}{l}i_{D} \\ i_{Q}\end{array}\right]=p(-\omega t) T_{32}^{T}\left[\begin{array}{l}i_{L a} \\ i_{L b} \\ i_{L c}\end{array}\right]$

With,

$p(-\omega t)=\left[\begin{array}{rr}\cos (-\omega t) & -\sin (-\omega t) \\ \sin (-\omega t) & \cos (-\omega t)\end{array}\right]$

And

$T_{32}^{T}=\sqrt{\frac{2}{3}}\left[\begin{array}{ccc}1 & -\frac{1}{2} & -\frac{1}{2} \\ 0 & \frac{\sqrt{3}}{2} & -\frac{\sqrt{3}}{2}\end{array}\right]$

Then, the diphase currents can be expressed in Fourier series as:

$\left[\begin{array}{l}i_{D} \\ i_{Q}\end{array}\right]=\sqrt{\frac{3}{2} i_{1}}\left[\begin{array}{l}\cos \left(\alpha_{1}\right) \\ -\sin \left(\alpha_{1}\right)\end{array}\right]+\sum_{n=2}^{N} \sqrt{\frac{3}{2}} i_{n}\left[\begin{array}{l}\cos \left((n-1) \omega t-\alpha_{n}\right) \\ \sin \left((n-1) \omega t-\alpha_{n}\right)\end{array}\right]$

These currents can be decomposed into two components:

- The continuous components 
$\left[\begin{array}{l}\overline{i_{D}} \\ \overline{i_{Q}}\end{array}\right]=\sqrt{\frac{3}{2} i_{1}}\left[\begin{array}{l}\cos \left(\alpha_{1}\right) \\ -\sin \left(\alpha_{1}\right)\end{array}\right]$

- The alternative components

$\left[\begin{array}{c}\widetilde{i}_{D} \\ \widetilde{i_{Q}}\end{array}\right]=\sum_{n=2}^{N} \sqrt{\frac{3}{2}} i_{n}\left[\begin{array}{l}\cos \left((n-1) \omega t-\alpha_{n}\right) \\ \sin \left((n-1) \omega t-\alpha_{n}\right)\end{array}\right]$

Two ADALINE are used to learn the two linear expression shown in equation (20) and to estimate the DC components, $\bar{i}_{D}$ and $\bar{i}_{Q}$, of the instantaneous $D Q$ currents. (23).

The resulting diphase harmonics currents are given by

$$
\begin{aligned}
& \widetilde{i_{D}}=i_{D}-\overline{i_{D}} \\
& \widetilde{i_{Q}}=i_{Q}-\overline{i_{Q}}
\end{aligned}
$$

These currents are written in three-phase system by applying successively transformation matrixes, $P(\omega t)$ and $T_{32}$. This enables computing reference currents to be injected in the power system

$$
\left[\begin{array}{l}
i_{\text {refa }} \\
i_{\text {refb }} \\
i_{\text {refc }}
\end{array}\right]=T_{32} p(\omega t)\left[\begin{array}{l}
\widetilde{i}_{D} \\
\widetilde{i_{Q}}
\end{array}\right]
$$

With space vector notation:

$$
\begin{aligned}
i_{D}(t) & =W_{D}{ }^{T} X_{D}(t) \\
i_{Q}(t) & =W_{Q}{ }^{T} X_{Q}(t)
\end{aligned}
$$

and

$$
\begin{aligned}
& W_{D}^{T}=\left[\begin{array}{llll}
\sqrt{\frac{3}{2}} i_{1} \cos \alpha_{1} & \sqrt{\frac{3}{2}} i_{5} \cos \alpha_{5} & \ldots \cdot \sqrt{\frac{3}{2}} i_{N} \cos \alpha_{N}
\end{array}\right] \\
& X_{D}^{T}=\left[\begin{array}{llll}
1 & \cos (4 \omega t) & \ldots & \sin (N-1) \omega t
\end{array}\right] \\
& W_{Q}^{T}=\left[\begin{array}{llll}
-\sqrt{\frac{3}{2} i_{1} \sin \alpha_{1}} & \sqrt{\frac{3}{2}} i_{5} \sin \alpha_{5} & \ldots . \sqrt{\frac{3}{2}} i_{N} \sin \alpha_{N}
\end{array}\right] \\
& X_{Q}^{T}=\left[\begin{array}{llll}
1 & \sin (4 \omega t) & \ldots & \cos (N-1) \omega t
\end{array}\right]
\end{aligned}
$$

The Currents decomposition and learning process are represented in Figure 4.

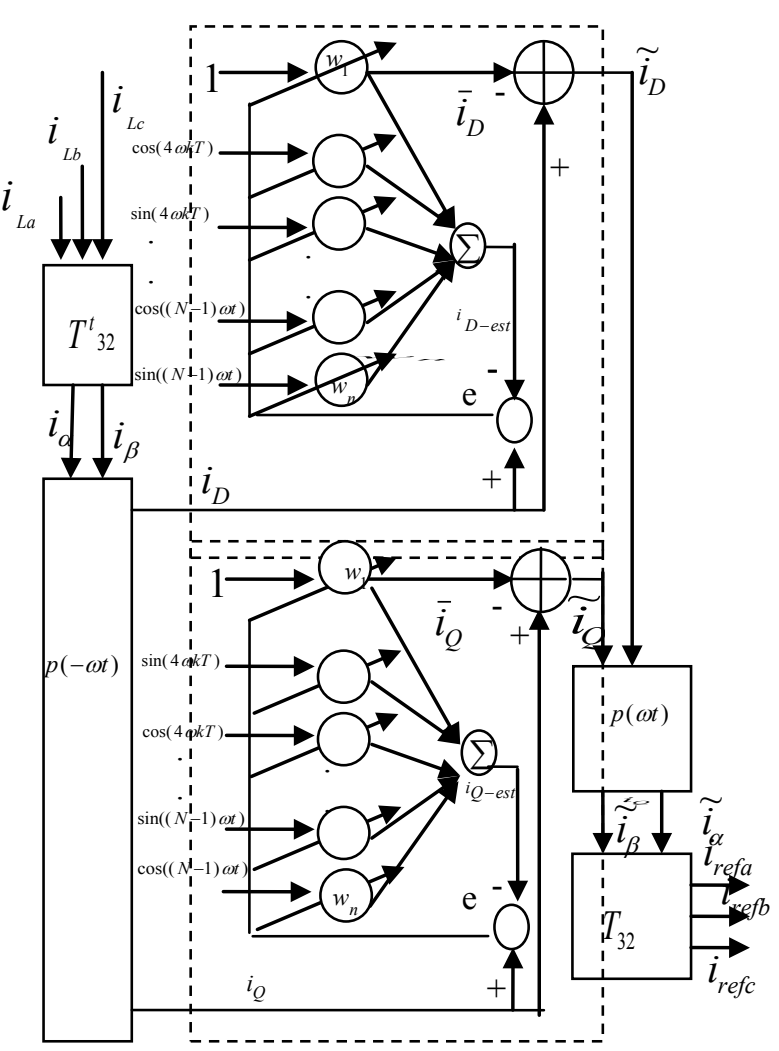

Fig.4. Diphase method current principle

\section{COMPARATIVE RESULTS}

\section{A. Implementation consideration}

In order to compare the $p$ - $q$ theory method with the diphase currents method mentioned in sections 3 and 4 respectively, different implementation aspects have to be considered.

Table 1 gives an idea of the capability and the complexity associated to each method. It can be seen that the instantaneous power method needs two low pass filters, a PLL to compute the direct voltage component and requires current and voltage $\alpha \beta$-space transformation.

The diphase current method needs two ADALINE for harmonics currents extraction and a Park's current transformation. The objective can be harmonic currents compensation, reactive power compensation and power factor correction.

Table.1. RESULTS OF METHODS COMPARISON

\begin{tabular}{|c|c|c|c|c|c|c|}
\hline $\begin{array}{c}\text { Identification } \\
\text { Methods }\end{array}$ & $\begin{array}{l}\text { Direct components } \\
\text { required }\end{array}$ & $\begin{array}{l}\text { Referential } \\
\text { required }\end{array}$ & $\begin{array}{l}\text { Harmonics } \\
\text { compensation }\end{array}$ & $\begin{array}{l}\text { Reactive power } \\
\text { compensation }\end{array}$ & $\begin{array}{l}\text { Valid for } \\
\text { tri /single-phase } \\
\text { system }\end{array}$ & $\begin{array}{l}\text { Harmonic extraction } \\
\text { method }\end{array}$ \\
\hline P-Q Theory & $v_{d}$ & $\alpha \beta$ & $\widetilde{p}, \widetilde{q}$ & $q$ & Three phase & Two LPF \\
\hline Diphase currents & - & $d q$ & $\widetilde{i}_{D}, \widetilde{i}_{Q}$ & $i_{Q}$ & Three phase & Two Adalines \\
\hline
\end{tabular}




\section{B. Simulation results}

Computer simulations with Matlab/Simulink are carried out to validate the performance of the new approach under industrial operating condition. We use the system parameters given in table 2 . The system is supplied from a balanced three-phase voltage sources feeding a threephase diode bridge rectifier with inductive load.

Table.2. System parameters

\begin{tabular}{|lll|}
\hline Utility source & Voltage (line -to-neutral) & $45 \mathrm{~V}_{\mathrm{rms}}$ \\
& Frequency & $50 \mathrm{~Hz}$ \\
& Source resistance & $0.1 \Omega$ \\
& Source inductance & $1 \mathrm{mH}$ \\
\hline Non-linear load & Load inductance & $100 \mathrm{mH}$ \\
& Load resistance & $100 \Omega$ \\
\hline \multirow{2}{*}{ Active Power filter } & APF inductance & $3 \mathrm{mH}$ \\
& APF capacitance & $400 \mu \mathrm{F}$ \\
\hline
\end{tabular}

The reference current extracted by the neural method called the diphase current as shown in the Figure 7 . It is similar to that identified by the conventional $p-q$ theory, method based on the instantaneous powers with a time response of $10 \mathrm{~ms}$ (Fig.6). The harmonic currents considered on the inputs of the two ADALINE for Diphase Current Method are the $5^{\text {th }}, 7^{\text {th }}, 11^{\text {th }}, 13$ th, $17^{\text {th }}$, and $19^{\text {th }}$.

Figure 5.a and Figure 11.a show that the line current from the load side has the classical quasi-square wave shape before compensation. The THDI is reduced from $27.91 \%$ (Fig.5.b) to $4.97 \%$ (Fig.8.b) for instantaneous power extraction and to $4.48 \%$ (Fig.9.b) for diphase currents method based on neural approach.
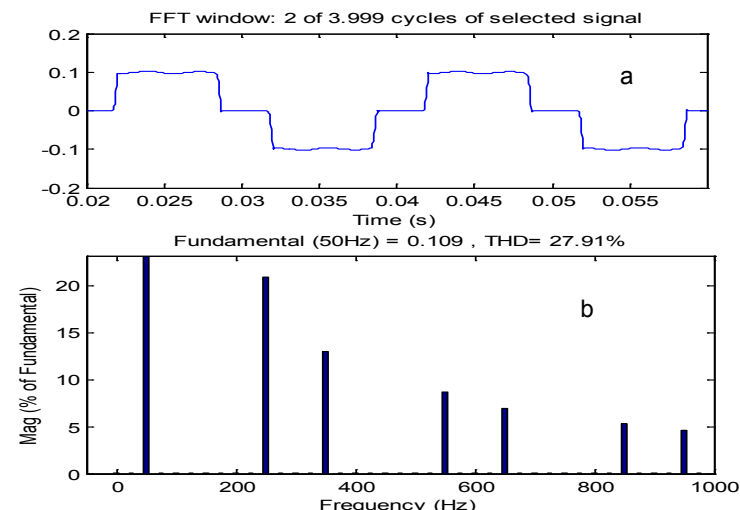

Fig.5. Load current (a) and its spectrum (b)

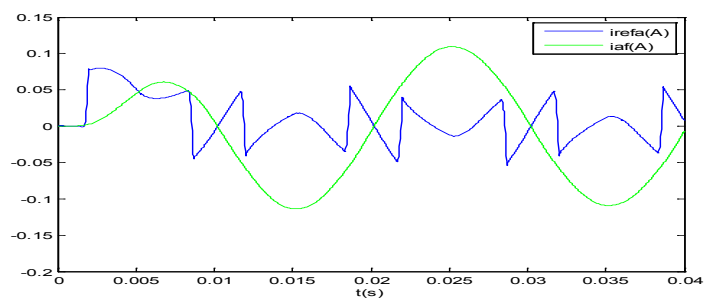

Fig.6. Fundamental and harmonic components of load current with $p-q$ theory

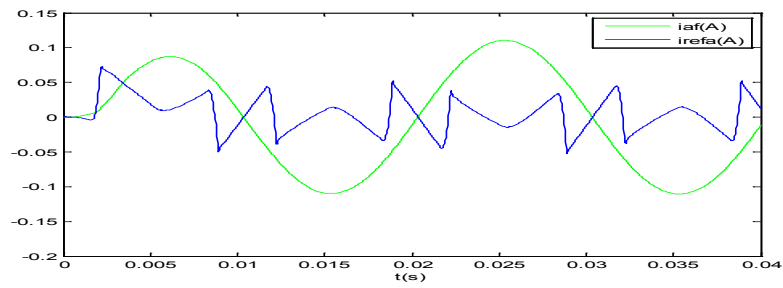

Fig.7.Fundamental and harmonic components of load current with neural method
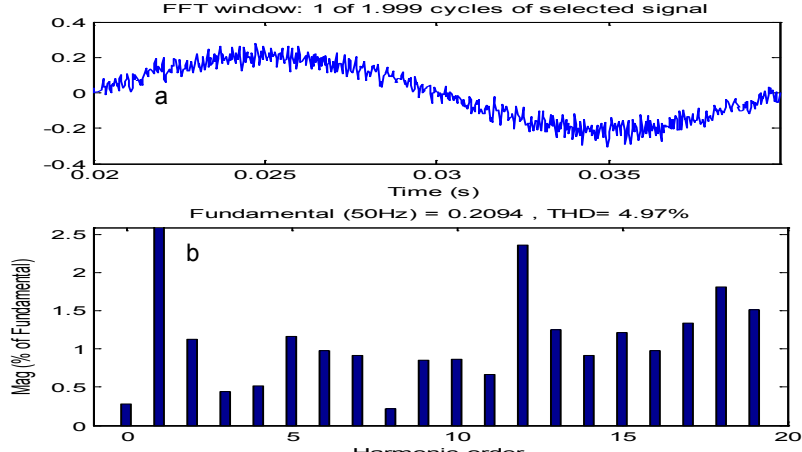

Fig.8. Source current wave form (a) and its harmonic spectrum (b) with instantaneous powers extraction
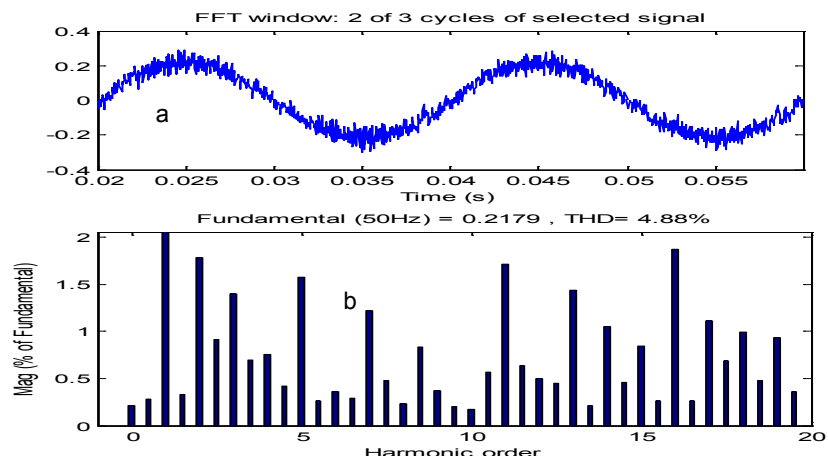

Fig.9. Source current wave form (a) and its harmonic spectrum (b) with diphase current extraction

\section{Experimental results}

In order to validate the simulated results, experimental tests in real time with a dSPACE Board were carried out. The system is supplied from a balanced three-phase voltage sources feeding a controlled three-phase bridge rectifier $\left(\alpha=0^{\circ}\right)$ with inductive load. The system parameters are illustrated in table 2 ; the two methods have been implemented on a dSPACE Board (DS1104) as shown in Figure 10. For fast response and in order to obtain the convergence of the LMS algorithm, the learning rate has been tested and chosen equal to 0.01 . This value is motivated by several tests and the input types of the ADALINE witch are the cosine and sine (they vary between -1 to +1 ). In this application, the program of the neural networks is written in $\mathrm{C}^{++}$code. The Current and voltage sensors have a reduction factor equal to 10 . Therefore, real current and voltage measurement are 10 times greater than the values taken during simulation and experimentation.

The experimental results obtained by neural extraction method presented in Figure 12.c shows a great efficiency in harmonic identification compared to the results of $p, q$ theory method illustrated in Figure 11.e. 
The waveforms of the estimate direct load current (Fig.12.a ( $\_$) and quadrate (Fig.12.b ( $)$) load current, are similar to the real direct load current (Fig.12.a ( )) and quadrature load current (Fig. 12.b ( )), from which it can be deduced that the LMS algorithm converge.

It can be seen that it is possible to estimate the $7^{\text {th }}$ harmonic current, as shown in Figure 13, the $5^{\text {th }}$ harmonic current Figure 14, and all harmonic currents considered in the inputs of the two ADALINE.

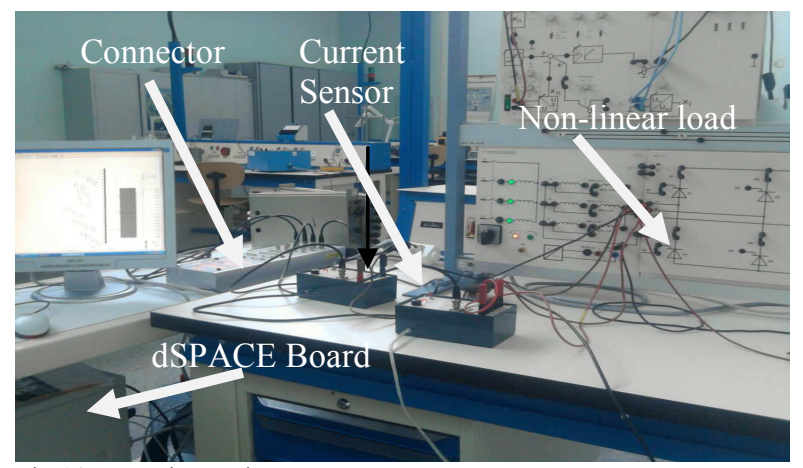

Fig.10. Experimental setup

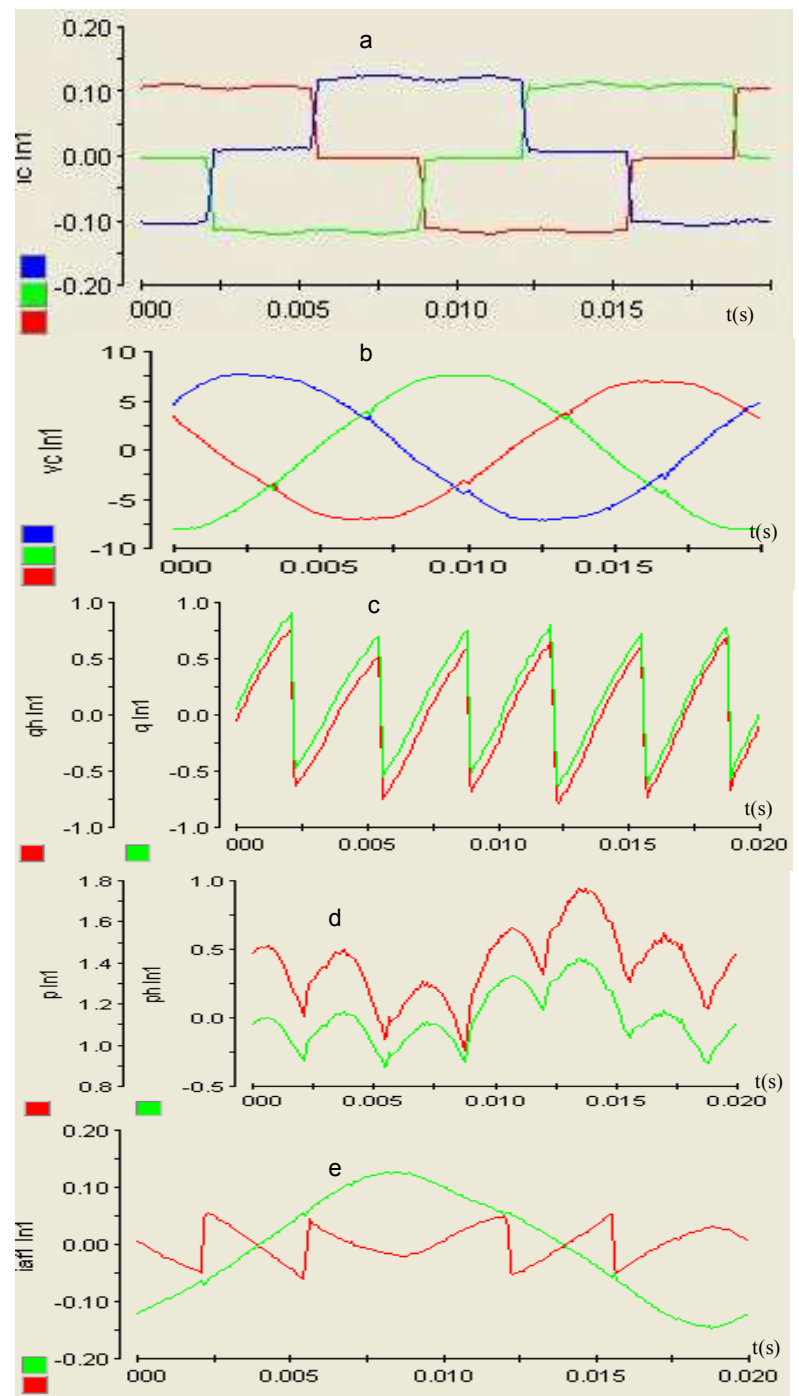

Fig.11. Experimental results in real time with $p-q$ Theory

a) Line currents of nonlinear load

b) Balanced supply voltages c) Reactive power $(\quad$ ) and its harmonic components $(\square)$

d) Active power $(\square)$ and its harmonic components ( $)$

e) Fundamental $(\square$ ) and harmonic load current $(\square)$
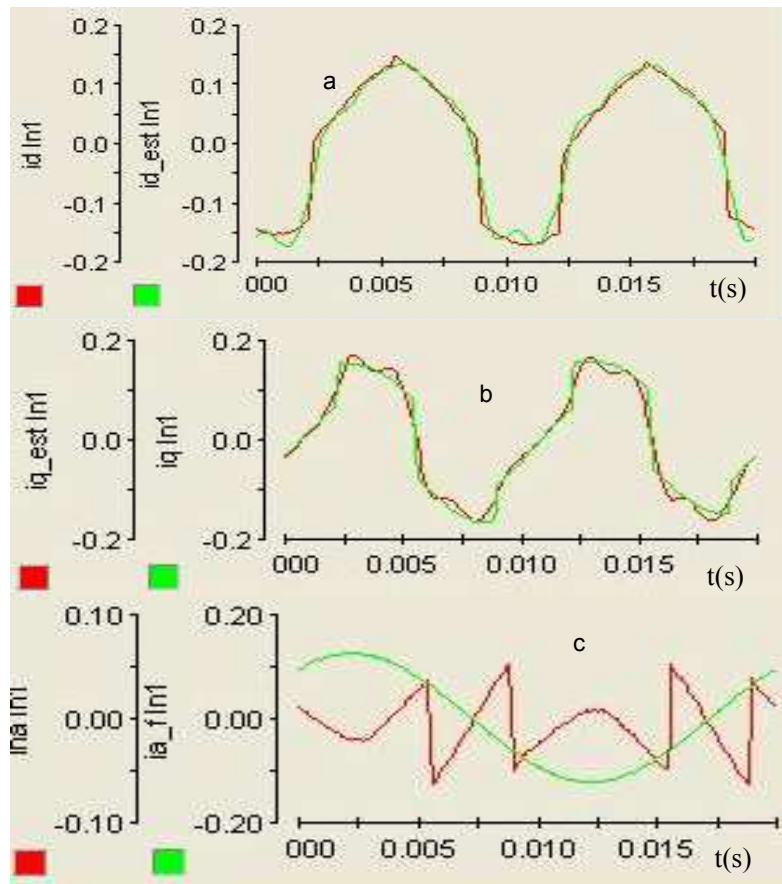

Fig.12. Real time experimental results with diphase currents Neuronal method

a) Real $(O$ ) and estimate ( $)$ direct load current

b) Real ( ) and estimate ( $\_$) quadrate load current

c) Fundamental ( $)$ and harmonic $(\square)$ load current

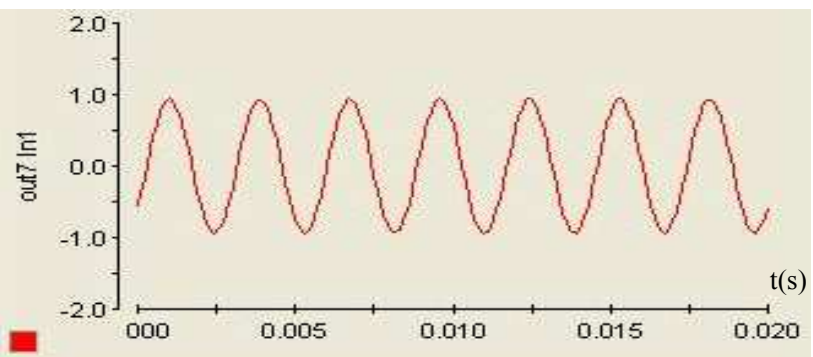

Fig.13. $7^{\text {th }}$ harmonic load current estimated with diphase currents Neuronal method without reduction factor sensor

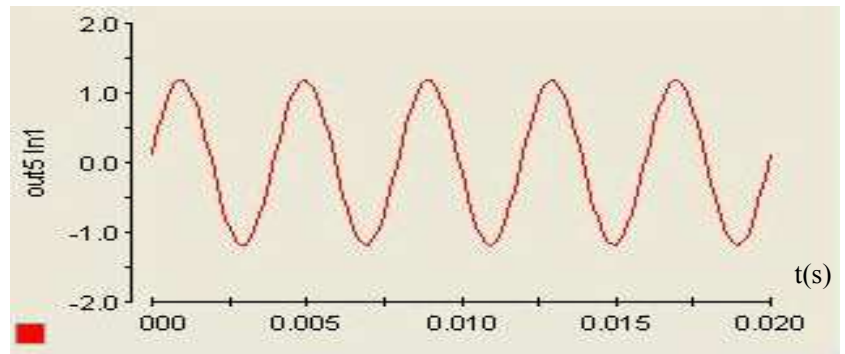

Fig.14. $5^{\text {th }}$ harmonic load current estimated with diphase currents Neuronal method without reduction factor sensor

The waveform of the fundamental load current deduced with $p-q$ theory (Fig. 11.e ( $)$ ) is affected by the bad wave form of the voltage supply when the experience is carried out. Then, it is necessary to calculate the direct voltage 
components with a phase looked loop before calculate the reference current.

\section{CONCLUSION}

The results obtained by the two harmonic extraction methods prove that accurate harmonic current extraction is obtained when the diphase current neural method is used. It can be also noted that the approach is different and the following conclusions can be drawn:

- If the system is unbalanced it is necessary to calculate the direct voltage components for the $p-q$ theory.

- The neural method can estimate the harmonic terms individually, and realize a selective compensation.

- In real time implementations, the neural method is the most suitable technique because its algorithm can be converted easily to another programming language, such as $\mathrm{C}^{++}$or JAVA. The convergence can be obtained by testing the learning rate algorithm.

- The architecture of the ADALINE enables the studied method to be easily implemented in real-time applications.

\section{Acknowledgments}

The authors like to thank the MIPS laboratory (France) for the technical support and the Algerian general direction of research for their financial support.

\section{REFERENCES}

[1] Akagi H, Watanabe E.H, Aredes M. Instantaneous Power Theory and Application to Power Conditioning.2007; Wiley/IEEE Press.

[2] Akagi H. Active Harmonic Filter. Proceedings of the IEEE 2005; 93(12): 2128-2141

[3] Zaveri N, and Chudasama A, Control strategies for harmonic mitigation and power factor correction using shunt active filter under various source voltage conditions. International Journal of Electrical Power \& Energy Systems 2012; 42(1): 661-671.

[4] Mendalek N, Al-Haddad K, Fnaiech F, and Dessaint L. A. Sliding Mode Control of 3-Phase 3-Wire Shunt Active Filter in the dq Frame. Proc. Of Electrical and Computer Engineering 2001; 2 : 765-769.

[5] Nath S, Sinha P, and Goswami S.K. A wavelet based novel method for the detection of harmonic sources in power systems. International Journal of Electrical Power \& Energy Systems 2012; 40(1): 54-61.

[6] Saad S, Zellouma L. Fuzzy logic controller for three-level shunt active filter compensating harmonics and reactive power. Electric Power Systems Research 2009; 79: 1337-1341.

[7] Mikkili S, and Panda A.K, Real-time implementation of PI and fuzzy logic controllers based shunt active filter control strategies for power quality improvement. International Journal of Electrical Power \& Energy Systems 2012; 43(1): 1114-1126.

[8] Ould Abdeslam D, Wira P, Mercklé J, Flieller D, and Chapuis Y.-A. A Unified Artificial Neural Network Architecture for Active Power Filters. IEEE Transactions on Industrial Electronics 2007; 54(1): 61-76.
[9] Durgasukumar G, Pathak M.K. Comparison of adaptive NeuroFuzzy-based space-vector modulation for two-level inverter. International Journal of Electrical Power \& Energy Systems 2012; 38(1): 9-19

[10] Li D, Chen Q, Jia Z, and Ke J. A Novel Active Power Filter With Fundamental Magnetic Flux Compensation. IEEE Trans. On Power Delivery 2004; 19(2): 799 - 805

[11] Hsieh G.-C, and Hung J. C. Phase-locked loop techniques. A survey. IEEE Transactions on Industrial Electronics 1996; 43(6): 609-615.

[12] Haykin S, Neural Networks: A Comprehension Foundation. 2nd ed. Prentice Hall; 1999.

[13] Widrow B, and Walach E. Adaptive Inverse Control. Prentice Hall; 1996.

[14] Bose B.K, Neural Network Applications in Power Electronics and Motor Drivers: An Introduction and Perspective. IEEE Transactions on Industrial Electronics 2007; 54(1): 14-33.

[15] A. Karami, Power system transient stability margin estimation using neural networks, International Journal of Electrical Power \& Energy Systems. 2011; 33(4): 983-991.

[16] Vardar K, Akpınar E, and Sürgevil T. Evaluation of reference current extraction methods for DSP implementation in active power filters. Electric Power Systems Research 2009; 79(10): 1342-1352.

[17] Joorabian M, Mortazavi S.S, and Khayyami A.A. Harmonic estimation in a power system using a novel hybrid Leas Squares-Adaline algorithm. 2009; Electric Power Systems Research, 79(1), 107-116.

[18] Sarkar A, Roy Choudhury S, and Sengupta S. A selfsynchronized ADALINE network for on-line tracking of power system harmonics. 2011; Measurement, 44(4): 784-790.

[19] Vasumathi B, Moorthi S. Implementation of hybrid ANN-PSO algorithm on FPGA for harmonic estimation. 2012; Engineering Applications of Artificial Intelligence, 25(3): 476-48

[20] Dash P. K, Swain D. P, Routray A, and Liew A. C. New Adaptive neural network approach for the estimation of power system frequency. Electric Power Systems Research 1997; 41(3): 203-210

[21] Sadinezhad I, Joorabian M. A novel frequency tracking method based on complex adaptive linear neural network state vector in power systems. Electric Power Systems Research 2009; 79(8): $1216-1225$

[22] Ai Q, Zhou Y, and Xu W. Adaline and its application in power quality disturbances detection and frequency tracking. Electric Power Systems Research 2007; 77(5-6): 462-469.

[23] Widrow B, and Lehr M. A. 30 years of adaptive neura networks: Perceptron, madaline, and back propagation. Proc. IEEE 1990; 79(9): 1415-1442.

[24] Flieller D, Ould Abdeslam D, Wira P, Merclé J. Distortion Identification and compensation Based on Artificial Neural Networks Using Symmetrical components of the Voltages and the Currents, Electronic Power System Research 2009; 79(7): 1145-1154. 